\title{
Pioglitazone Prevents Capillary Rarefaction in Streptozotocin-Diabetic Rats Independently of Glucose Control and Vascular Endothelial Growth Factor Expression
}

\author{
Astrid Ashoff ${ }^{a}$ Fatimunnisa Qadric Reinhard Eggers ${ }^{\mathrm{b}}$ Olaf Jöhren ${ }^{\mathrm{a}}$ \\ Walter Raasch ${ }^{a} \quad$ Andreas Dendorfer $^{a}$ d

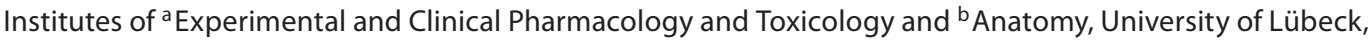 \\ Lübeck, 'Max Delbrück Center for Molecular Medicine, Berlin, and ' Walter Brendel Centre of Experimental \\ Medicine, Ludwig-Maximilians-University Munich, Munich, Germany
}

\section{Key Words}

Diabetic angiopathies • Capillaries • Rarefaction •

Peroxisome proliferator-activated receptor- $\gamma$ •

Vascular endothelial growth factor • Oxygen radicals

\begin{abstract}
Background/Aims: Reduction of capillary network density occurs early in the development of metabolic syndrome and may be relevant for the precipitation of diabetes. Agonists of the peroxisome proliferator-activated receptor (PPAR)- $\gamma$ transcription factor are vasculoprotective, but their capacity for structural preservation of the microcirculation is unclear. Methods: Male Wistar rats were rendered diabetic by streptozotocin and treated with pioglitazone in chow for up to 12 weeks. Capillary density was determined in heart and skeletal muscle after platelet endothelial cell adhesion molecule-1 (PECAM-1) immunostaining. Hallmarks of apoptosis and angiogenesis were determined. Results: Capillary density deteriorated progressively in the presence of hyperglycemia (from $971 / \mathrm{mm}^{2}$ to $475 / \mathrm{mm}^{2}$ in quadriceps muscle during 13 weeks). Pioglitazone did not influence plasma
\end{abstract}

\section{KARGER}

Fax +4161306 1234

E-Mail karger@karger.ch

www.karger.com
(C) 2012 S. Karger AG, Basel

$1018-1172 / 12 / 0493-0260 \$ 38.00 / 0$

Accessible online at:

www.karger.com/jvr glucose, left ventricular weight, or body weight but nearly doubled absolute and relative capillary densities compared to untreated controls ( $1.2 \mathrm{vs.} 0.6$ capillaries/myocyte in heart and 1.5 vs. 0.9 capillaries/myocyte in quadriceps muscle) after 13 weeks of diabetes. No antiapoptotic or angiogenic influence of pioglitazone was detected while a reduced expression of hypoxia-inducible factor- $3 \alpha$ and PPAR coactivator- $1 \alpha$ (PGC-1 $\alpha$ ) mRNA as well as vascular endothelial growth factor (VEGF) protein possibly occurred as a consequence of improved vascularization. Conclusion: Pioglitazone preserves microvascular structure in diabetes independently of improvements in glycemic control and by a mechanism unrelated to VEGF-mediated angiogenesis.

Copyright $\odot 2012$ S. Karger AG, Basel

\section{Introduction}

Diabetes is associated with a variety of vascular pathologic processes leading to micro- and macrovascular disease. Microvascular alterations are importantly involved in diabetic organ damage, e.g. nephropathy and retinop- 
athy, and include dysregulation, enhanced permeability, and pathologic angiogenesis, as well as capillary rarefaction. The latter phenomenon can be differentiated into a functional insufficiency of capillary recruitment and a structural reduction of capillary density, both of which impair tissue perfusion in a reversible or chronic manner, respectively [1]. Structural deterioration of the capillary network has consistently been observed in models of type 2 diabetes and hypertension, the hallmarks of the socalled 'metabolic syndrome' [2,3]. Interestingly, capillary rarefaction is even present in normotensive men with a hypertensive disposition [4] and correlates inversely with insulin resistance in nondiabetic men [5], thereby suggesting a causal involvement in the precipitation of both diseases. Pathomechanisms of metabolic syndrome such as an increased demand of vascular perfusion pressure and an impairment of metabolite exchange may well be attributed to capillary rarefaction which is therefore considered as a promising target of therapy [6-8].

Activators of the peroxisome proliferator-activated receptor- $\gamma$ (PPAR- $\gamma$ ) transcription factor, e.g. the thiazolidinediones (TZDs), increase insulin sensitivity and therefore ameliorate hyperglycemia in type 2 diabetes. Apart from this, TZDs display a broad spectrum of activities, most of which are therapeutically beneficial and associated with anti-inflammatory and vasoprotective mechanisms [9]. It has been proposed that reduction in the progression of type 2 diabetes and of diabetic nephropathy is a consequence of such pleiotropic actions of TDZs. Experimentally, the TZD pioglitazone (PIO) preserves the function of glomerular microvessels even in a rat model of streptozotocin (STZ)-induced diabetes which excludes a concomitant influence on glucose metabolism [10]. Since TZDs increase the availability of nitric oxide through direct activation of NO synthase and reduction of inflammation [11], such treatment may target one major pathomechanism of structural diabetic damage of the microcirculation [12]. We therefore hypothesized that treatment with PIO might prevent diabetic capillary rarefaction in a manner independent of its antihyperglycemic activity.

\section{Material and Methods}

\section{Experimental Protocols}

All experiments were approved by the Authorities of SchleswigHolstein and complied with principles of laboratory animal care. A total of 50 male Wistar rats aged 8 weeks (Charles River, Sulzfeld, Germany) were used in 3 experimental protocols: (1) time course of capillary rarefaction (nondiabetic control rats, and rats after 5, 7, and 13 weeks of diabetes; $n=5),(2)$ long-term treatment [diabetic rats fed with standard chow (Altromin, Lage, Germany), or chow supplemented with $0.01 \%$ PIO (Takeda Pharma, Germany) for 12 weeks; $n=10$ ], and (3) short-term treatment (nondiabetic control and STZ-diabetic groups, the latter treated with either solvent or PIO, $10 \mathrm{mg} / \mathrm{kg}$ body weight by gavage for 4 days; $\mathrm{n}=3-4)$. Diabetes was induced by i.p. injection of STZ $(75 \mathrm{mg} / \mathrm{kg}$ body weight in citrate buffer, $0.1 \mathrm{~mol} / \mathrm{l}, \mathrm{pH} 4.5)$. Blood glucose levels were determined 2 days after STZ injection and had to exceed $22 \mathrm{mmol} / \mathrm{l}$ for further inclusion of the animal. Treatments with PIO began 8 days after induction of diabetes with the provision of supplemented chow or once-daily oral application. Blood pressure and heart rate were determined by tail plethysmography [13]. Rats were killed by i.p. injection of pentobarbital $(100 \mathrm{mg} / \mathrm{kg}$ body weight).

\section{Capillary Morphometry}

Heart and quadriceps femoris muscles were quickly excised and cut for the preparation of transverse disks of the left ventricle and the rectus femoris portion which were snap frozen in 2-methylbutane $\left(-80^{\circ} \mathrm{C}\right)$. After mounting in Lipshaw embedding matrix, $10-\mu \mathrm{m}$-thick slices were generated with a cryotome (CM 3050; Leica, Germany). Capillary endothelium was labelled with a primary antibody against platelet endothelial cell adhesion molecule-1 (PECAM-1, mouse anti-rat CD31, 1:1,000; Serotec, USA) which was detected using the Biotin-StreptavidinHRP technique (Vectastain Elite ABC; Vector Laboratories, Burlingame, Calif., USA). Appropriate negative controls were included. Nuclei were counterstained with hemalaun. In each sample, 20 fields with an area of $0.0357 \mathrm{~mm}^{2}$ each were selected following the criteria of Weidner [14] before they were photographed and analyzed for the number of stained capillaries and myocytes. Apoptotic nuclei were visualized in cryosections using the TUNEL reaction (DeadEnd Fluorometric TUNEL System; Promega, USA).

\section{Biochemical Analysis}

Plasma glucose was determined in venous blood using the glucose-oxidase reaction (Elite XL; Bayer, Germany). Urine was sampled from the bladder at the end of the experiment and analyzed for albumin by nephelometry (Clinical Laboratory, University Clinics, Lübeck, Germany). The activity of caspases 3 and 7 was measured in homogenates of quadriceps muscle using a luminescent substrate according to the manufacturer's recommendations (Caspase-Glo 3/7; Promega). Vascular endothelial growth factor (VEGF)-A was determined in plasma and in homogenates of quadriceps muscle (2 $\mathrm{mg}$ protein/ml) using a commercial ELISA (Quantikine; R\&D Systems, Minneapolis, Minn., USA). mRNA was extracted, reversely transcribed, and quantified by real-time PCR as previously described [15].

\section{Materials}

All substances were obtained in highest quality from either Sigma (Taufkirchen, Germany) or Merck (Darmstadt, Germany) unless stated otherwise.

\section{Statistics}

Data were evaluated using Student's t test or one-way ANOVA as appropriate. $\mathrm{p}<0.05$ was considered statistically significant. 

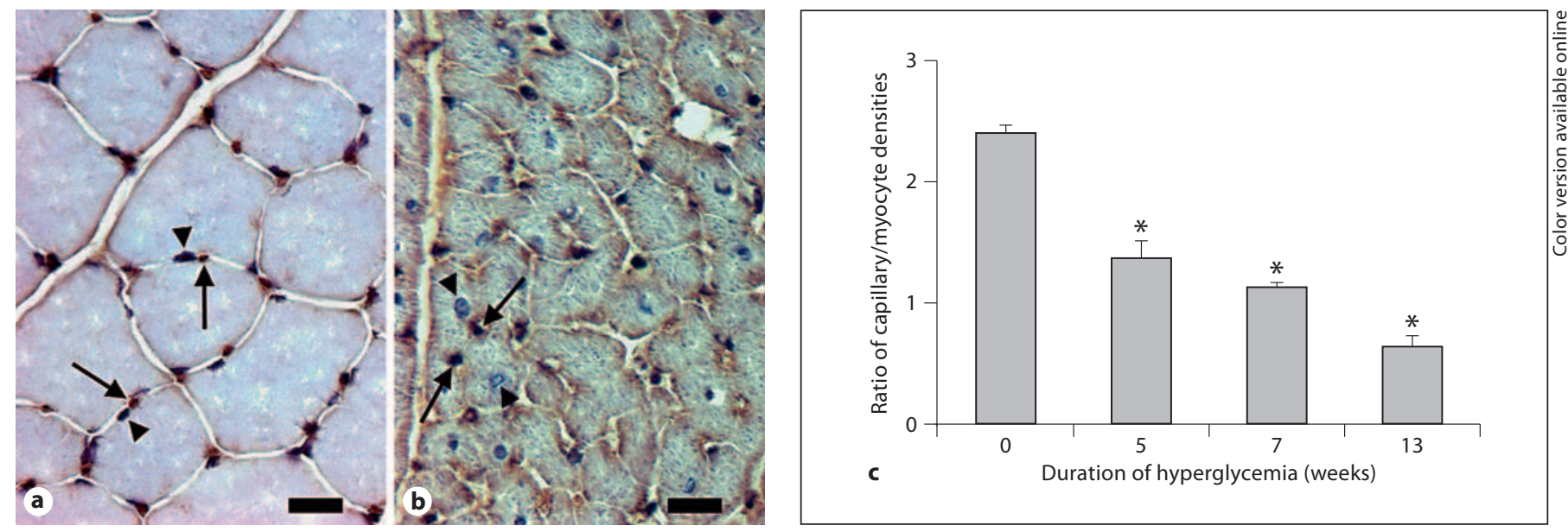

Fig. 1. Identification and time course of capillary rarefaction in skeletal and heart muscle. The images depict capillaries stained for PECAM-1 (arrows) and nuclei (arrowheads) in the quadriceps femoris muscle (a) and the left ventricular myocardium (b). Scale bars $=20 \mu \mathrm{m}$. c The graph demonstrates the decline in the ratio of capillary and myocyte densities in quadriceps femoris muscle in response to a prolonged period of hyperglycemia (* $\mathrm{p}<0.05$ vs. normoglycemic control, $\mathrm{n}=5$ ).

\section{Results}

Time Course of Capillary Rarefaction

Within 2 days of injection, STZ provoked a prominent hyperglycemia that was accompanied by typical symptoms of diabetes (glucosuria, polydipsia). During 13 weeks of diabetes, a slight rise in systolic blood pressure (from $104 \pm 2$ to $128 \pm 3 \mathrm{~mm} \mathrm{Hg}$, p < 0.05) was observed while plasma glucose $(604 \pm 8 \mathrm{mg} / \mathrm{dl})$, body weight $(280$ $\pm 18 \mathrm{~g})$, and left ventricular weight $(542 \pm 40 \mathrm{mg})$ remained constant. A progressive loss of capillaries occurred in the quadriceps muscle regarding the area density (from $971 \pm 86$ to $475 \pm 51 \mathrm{~mm}^{-2}$ after 13 weeks) as well as the number of capillaries per myocyte (fig. 1).

\section{Microvascular Protection by PIO}

Rats included in the placebo group of the long-term treatment study developed a degree of capillary rarefaction similar to that of the group with 13 weeks of diabetes in the kinetics study (fig. 2). Ingestion of PIO for 12 weeks in the active treatment group did not influence basic metabolic parameters but significantly reduced blood pressure and urinary albumin excretion (table 1). When treatment was begun 8 days after the induction of diabetes, PIO consistently attenuated the development of capillary rarefaction in skeletal as well as heart muscle (fig. 1b) but did not fully preserve the capillary density of nondiabetic rats (971 $\pm 86 \mathrm{~mm}^{-2}$ in quadriceps muscle). While PIO had no influence on myocyte size in skeletal muscle, it slightly decreased the number of myocytes per unit of area in the myocardium (fig. 1c). Visualization of apoptosis in myocardial tissue revealed a very low incidence (less than 3 TUNEL-positive cells in each preparation) which was restricted to nonmyocytes. Biochemical assessment of caspases 3 and 7 demonstrated an increase in the combined activity in the PIO-treated group (table 1). The mRNA expression of hypoxia-induced factors and their target genes [VEGF, glucose transporter 1 (Glut1), endothelial nitric oxide synthase (NOS3)] was not affected by PIO, with the exception of hypoxia-inducible factor (HIF)-3 $\alpha$ whose transcript levels were reduced (table 1). PIO reduced the abundance of VEGF protein in plasma (table 1) but induced no significant alteration in quadriceps muscle $(63.2 \pm 7.6$ vs. $67.7 \pm 7.9 \mathrm{pg} / \mathrm{mg}$ protein for $\mathrm{PIO}$ vs. the control group, respectively). The mRNA expression in quadriceps muscle of further factors with angiogenic potential was either unchanged (NOS3) or reduced (PPAR coactivator $1 \alpha$; PGC-1 $\alpha$ ) (table 1 ).

\section{Effects of PIO on Apoptosis in Short-Term Diabetes}

To demonstrate a possible induction of apoptosis early in the development of diabetes, rats were rendered diabetic for a total of 12 days and treated during the final 4 days with either PIO or placebo. Again, the incidence of TUNEL-positive cells was too low to be quantified morphologically. Compared with a nondiabetic control 

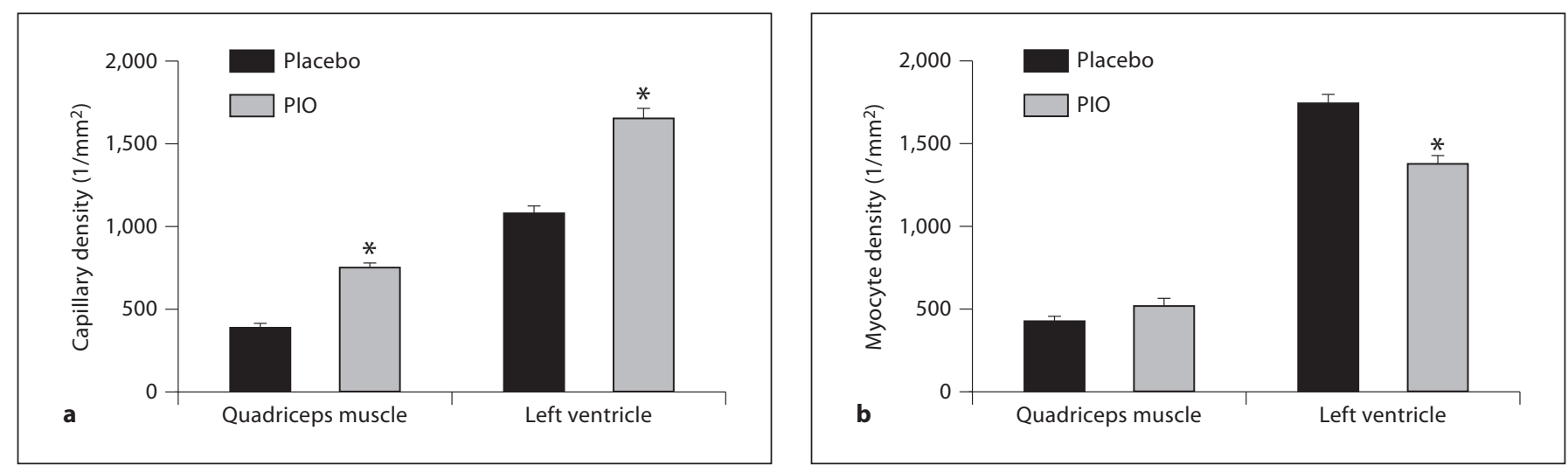

Fig. 2. Influence of PIO on capillary (a) and myocyte (b) densities after 13 weeks of induced diabetes. Treatment with PIO greatly improved the area densities in the quadriceps femoris muscle and the left ventricular myocar$\operatorname{dium}\left(\mathbf{a} ;{ }^{*} \mathrm{p}<0.05\right.$ vs. placebo-treated control, $\left.\mathrm{n}=10\right)$.

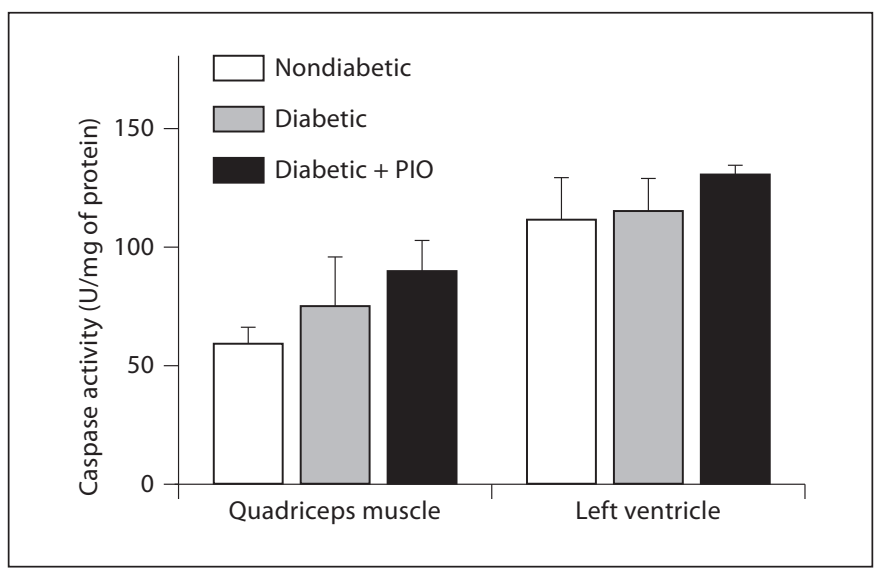

Fig. 3. Apoptosis in skeletal and heart muscle after 12 days of induced diabetes. Neither an increase in apoptosis in comparison to nondiabetic rats nor an influence of PIO treatment could be verified according to the combined activities of caspases 3 and $7(\mathrm{n}=$ $3-4)$.

group, the combined activities of caspases 3 and 7 were identical in the skeletal muscle of diabetic animals, and PIO developed a tendency to increase caspase activities further (fig. 3). Compared to skeletal muscle, caspases were slightly more active in the myocardium and likewise were not influenced by diabetes or PIO treatment (fig. 3). While 12 days of diabetes induced no difference in VEGF protein concentration in plasma, the tissue content of VEGF in skeletal muscle was reduced in diabetic (142 \pm $65 \mathrm{pg} / \mathrm{mg}$ protein) compared to nondiabetic rats (360 \pm $55 \mathrm{pg} / \mathrm{mg}$ protein) and it was diminished even further by concomitant treatment with PIO (67 $\pm 2 \mathrm{pg} / \mathrm{mg}$ protein).
Table 1. General and metabolic parameters of STZ-diabetic rats treated for 12 weeks with either placebo or PIO

\begin{tabular}{lcc}
\hline & Placebo & PIO \\
\hline Plasma glucose, mg/dl & $592 \pm 5$ & $588 \pm 12$ \\
Food intake, g/day & $42.4 \pm 1.6$ & $40.8 \pm 1.2$ \\
Body weight, g & $264 \pm 12$ & $237 \pm 13$ \\
Left ventricular weight, mg & $607 \pm 15$ & $593 \pm 28$ \\
Blood pressure, mm Hg & $125 \pm 2$ & $114 \pm 3^{*}$ \\
Heart rate, bpm & $349 \pm 17$ & $347 \pm 10$ \\
Urinary albumin, mg/l & $144 \pm 40$ & $56 \pm 10^{*}$ \\
Plasma VEGF-A, pg/ml & $90.1 \pm 5.3$ & $72.8 \pm 2.4^{*}$ \\
Caspase activity, U/mg protein & $16.3 \pm 1.2$ & $22.1 \pm 2.0^{*}$ \\
HIF-1 $\alpha$, copies/pg RNA & $26.6 \pm 3.8$ & $20.7 \pm 3.6$ \\
HIF-2 $\alpha$, copies/pg RNA & $168 \pm 16$ & $174 \pm 9$ \\
HIF-3 $\alpha$, copies/pg RNA & $6.07 \pm 1.16$ & $2.04 \pm 0.63^{*}$ \\
HIF-1 $\beta$, copies/pg RNA & $18.6 \pm 1.0$ & $15.8 \pm 1.3$ \\
Glut1, copies/pg RNA & $6.65 \pm 0.32$ & $5.90 \pm 0.29$ \\
VEGF-A, copies/pg of RNA & $44.4 \pm 4.1$ & $35.7 \pm 3.7$ \\
NOS3, copies/pg RNA & $32.5 \pm 1.2$ & $32.8 \pm 1.8$ \\
PGC-1 $\alpha$, copies/pg RNA & $2,637 \pm 214$ & $1,911 \pm 118^{*}$ \\
\hline
\end{tabular}

Caspase activities and mRNA expression profiles were determined in quadriceps muscle. $\mathrm{n}=10,{ }^{*} \mathrm{p}<0.5$ vs. placebo.

\section{Discussion}

This study is the first to demonstrate that capillary rarefaction occurs in the rat model of STZ-induced diabetes. Such damage to the microcirculation is a known consequence of type 2 diabetes (e.g. in the Zucker rat [2]) and of hypertension (genetic or induced by glucocorti- 
coids or by inhibition of NO synthesis $[3,16,17])$. Together with analogous observations in STZ-treated mice [18, 19], the present study indicates a general microvascular pathophysiology of hyperglycemia which is independent of further diabetic implications, such as hypertension or endocrine derangement. Importantly, capillary deterioration in our model proceeds for many weeks so that a direct vascular toxic action of STZ, which has a half-life of less than $1 \mathrm{~h}$, can be excluded. The development of capillary rarefaction may involve various detrimental factors, but a pivotal role in diabetes as well as hypertension has been ascribed to the abundance of oxygen radicals in relation to a reduced NO bioavailability $[12,20]$. This imbalance may trigger apoptosis of endothelial cells or pericytes either directly or through activation of NF- $\mathrm{BB}[21$, 22]. High glucose concentrations in vitro stimulate several pathways in endothelial cells that lead to enhanced mitochondrial superoxide production, thereby triggering specific diabetic alterations [23]. The causal role of oxygen radicals for the development of capillary rarefaction in vivo can be deduced from the protective action of radical scavengers $[12,20]$.

Although a variety of vascular actions have been reported for TZDs, little is known about a potential protection of the microcirculation. Studies in the context of diabetes have focused on proangiogenic mechanisms that were induced by ischemia or simulated in vitro $[24,25]$. In contrast, the present study targeted the deterioration of microvascular structure imposed by diabetes alone. Since PIO did not influence hyperglycemia in the STZ model, its protective action must have resulted from interference with specific downstream targets which most likely converge on the relationship of $\mathrm{NO}$ and oxygen radicals. In the setting of diabetic vasculopathy, TZDs have been demonstrated to reduce oxidative stress by activation of NO synthase, by suppression of superoxide generation and down-regulation of NADPH oxidase, and by various anti-inflammatory actions, e.g. inhibition of $\mathrm{NF}-\kappa \mathrm{B}$ in various cell types [9-11]. The ability of TZDs to counteract the sequels of NO deficiency is underlined by the observation that rosiglitazone delayed capillary loss in a model of pharmacological NO-synthase inhibition [17]. In view of these well-characterized antioxidant activities of PPAR- $\gamma$ agonists, it appeared to be obvious that these pathways would contribute to vascular protection observed in STZ-induced diabetes, so that their further delineation was not a primary goal of our in vivo study.

Instead, our analyses were directed toward the possible antiapoptotic and proangiogenic components of protection. Although hyperglycemia has been shown to in- duce apoptosis of vascular cells [21, 22], no increase in caspase activity was detected in our study in skeletal or ventricular muscle after 12 days of diabetes (fig. 3). This may be explained by the chronic presence of hyperglycemia that would enable as little as $10 \%$ enhancement of apoptosis to produce long-term alterations in the microcirculation [16]. Caspase activation to such little extent indeed occurred in skeletal muscle of diabetic rats, but the impact of diabetes could not be verified statistically (fig. 3). Even more surprising, PIO was found to increase caspase activities in the skeletal muscle of diabetic rats, indicating an increased rate of apoptosis (table 1). This contradicts the presumed antiapoptotic action of PIO in endothelial cells. However, it cannot be excluded that an antiapoptotic influence on a specific cell population might have been masked by an increase in apoptosis in other tissues since apoptotic nuclei were too infrequent to allow an analysis of cell type distribution. In fact, induction of apoptosis in nonendothelial cells appears quite feasible since PPAR- $\gamma$ agonists are known for such activities in vascular smooth muscle cells and macrophages and may even counteract inflammation in this way [26, 27].

An alternative explanation for the preservation of capillary numbers by PIO might be related to a proangiogenic influence. Despite the fact that the vascular pathophysiology of diabetes includes a proliferative component, an insufficiency of compensatory angiogenesis is evident as well, as exemplified by an impairment of wound healing. Low protein levels of VEGF were associated with capillary rarefaction in the present study as well as in kidneys of diabetic patients [28] and may originate from a deficient response of VEGF expression to stimulation via HIF [29]. Typically, TZDs stimulate VEGF expression and improve the angiogenic response to ischemia [24, 30,31]. However, such activity was observed in our study. VEGF concentrations in plasma were rather decreased by PIO, and mRNA expression in skeletal muscle showed a parallel, albeit statistically insignificant, tendency (table 1). Since PIO may provoke capillary protection by restoring the sensitivity of HIF, we investigated the mRNA expression of all known $\alpha$-units of HIF, the cofactor HIF-1 $\beta$, some target genes (VEGF-A, Glut1, NOS3), and PGC- $1 \alpha$, the latter being able to induce VEGF expression in an HIF-independent manner [32]. However, no evidence was found for an influence of PIO on any HIF subtype, with the exception of HIF-3 $\alpha$ (table 1). This subtype is known to be transcriptionally induced by hypoxia and in cardiac failure $[15,33]$ and is considered to be a negative regulator of typical HIF activities. Taken 
together, the reduced expression of HIF- $3 \alpha$ and of PGC$1 \alpha$ in association with reduced plasma levels of VEGF protein bear no indication of an involvement of VEGF in the vasculoprotective action of PIO. Rather, these alterations may be interpreted as secondary consequences of an improved nutritional supply that has been achieved through the enhancement of capillary density.

A confounding influence on the morphological analyses of this study arises from the development of diabetic cardiomyopathy. Cardiac remodeling in STZ-diabetic rats can include myocyte loss and compensatory hypertrophy that would reduce the vascular area density of even a constant number of microvessels. However, the loss of microvessels observed in this study greatly outnumbered any potential myocyte decay that might have occurred, as exemplified by the progressive decrease in the capillary/myocyte ratio in skeletal muscle (fig. 1). In the present study, PIO treatment decreased cardiomyocyte density (fig. 2) so that its preservative action in terms of the relative capillary density could even have exceeded the clear increase in area density (fig. 2). As such, diabetic cardiomyopathy exerts no decisive influence on the interpretation of capillary rarefaction and its amelioration by PIO. However, PIO tended to enhance rather than reverse diabetic cardiac hypertrophy, as indicated by the reduction of myocyte density. This structural alteration is a typical consequence of PPAR- $\gamma$ activation and appears to be caused by fluid accumulation and hemodynamic overload [34]. Additional findings about direct myocardial actions of PPAR- $\gamma$ are ambiguous. Pharma- cological activation of PPAR- $\gamma$ may be cardioprotective [35], while its transgenic expression induces metabolic cardiomyopathy [36]. As such, there must be concern that the increase in caspase activities observable in PIO-treated rats might indicate myocyte loss. The present study cannot exclude this possibility; however, myocyte apoptosis was not evident in TUNEL-stained specimens of heart or skeletal muscle, and a recent study even reported the prevention of apoptosis by a TZD in the myocardium of a corresponding STZ model [37]. Since the possibility of such adverse actions would be crucial for the evaluation of the cardiac safety of TZDs, studies with high sensitivity and high degrees of tissue discrimination should be performed.

In conclusion, PPAR- $\gamma$ activation by PIO has been shown to protect the microvasculature of skeletal and cardiac muscle from structural decline. This protection occurs in the absence of metabolic effects of PIO and seems to be unrelated to angiogenic actions of VEGF. An increase in capillary density should contribute to restoration of insulin sensitivity and to retardation of diabetes manifestation, achievements that represent the hallmarks of TZDs in clinical therapy.

\section{Acknowledgements}

The authors are grateful to Mrs. Gudrun Vierke for her excellent technical assistance and to Dr. Julian P. Keogh for assisting in the editing of the manuscript.

\section{References}

1 Levy BI, Schiffrin EL, Mourad JJ, Agostini D, Vicaut E, Safar ME, Struijker-Boudier HA: Impaired tissue perfusion: a pathology common to hypertension, obesity, and diabetes mellitus. Circulation 2008;118:968-976.

2 Frisbee JC: Hypertension-independent microvascular rarefaction in the obese Zucker rat model of the metabolic syndrome. Microcirculation 2005; 12:383-392.

3 Prewitt RL, Chen II, Dowell R: Development of microvascular rarefaction in the spontaneously hypertensive rat. Am J Physiol 1982; 243:H243-H251.

4 Noon JP, Walker BR, Webb DJ, Shore AC, Holton DW, Edwards HV, Watt GC: Impaired microvascular dilatation and capillary rarefaction in young adults with a predisposition to high blood pressure. J Clin Invest 1997;99:1873-1879.
5 Lillioja S, Young AA, Culter CL, Ivy JL, Abbott WG, Zawadzki JK, Yki-Järvinen $\mathrm{H}$, Christin L, Secomb TW, Bogardus C: Skeletal muscle capillary density and fiber type are possible determinants of in vivo insulin resistance in man. J Clin Invest 1987;80:415424.

6 Frisbee JC, Samora JB, Peterson J, Bryner R: Exercise training blunts microvascular rarefaction in the metabolic syndrome. Am J Physiol Heart Circ Physiol 2006;291:H2483$\mathrm{H} 2492$.

7 Goodwill AG, Frisbee SJ, Stapleton PA, James ME, Frisbee JC: Impact of chronic anticholesterol therapy on development of microvascular rarefaction in the metabolic syndrome. Microcirculation 2009;16:667-684.

8 Battegay EJ, de Miguel LS, Petrimpol M, Humar R: Effects of anti-hypertensive drugs on vessel rarefaction. Curr Opin Pharmacol 2007;7:151-157.
9 Duan SZ, Usher MG, Mortensen RM: Peroxisome proliferator-activated receptorgamma-mediated effects in the vasculature. Circ Res 2008;102:283-294.

10 Ohga S, Shikata K, Yozai K, Okada S, Ogawa D, Usui H, Wada J, Shikata Y, Makino H: Thiazolidinedione ameliorates renal injury in experimental diabetic rats through antiinflammatory effects mediated by inhibition of NF-kappaB activation. Am J Physiol Renal Physiol 2007;292:F1141-F1150.

11 Polikandriotis JA, Mazzella LJ, Rupnow HL, Hart CM: Peroxisome proliferator-activated receptor gamma ligands stimulate endothelial nitric oxide production through distinct peroxisome proliferator-activated receptor gamma-dependent mechanisms. Arterioscler Thromb Vasc Biol 2005;25:1810-1816. 
12 Frisbee JC: Reduced nitric oxide bioavailability contributes to skeletal muscle microvessel rarefaction in the metabolic syndrome. Am J Physiol Regul Integr Comp Physiol 2005;289:R307-R316.

13 Dendorfer A, Dominiak P, Tempel K, Raasch W: Peripheral sympatholytic actions of four AT1 antagonists: are they relevant for longterm antihypertensive efficacy? J Hypertens 2005;23:1861-1867.

14 Weidner N: Current pathologic methods for measuring intratumoral microvessel density within breast carcinoma and other solid tumors. Breast Cancer Res Treat 1995;36:169180.

15 Heidbreder M, Fröhlich F, Jöhren O, Dendorfer A, Qadri F, Dominiak P: Hypoxia rapidly activates HIF-3alpha mRNA expression. FASEB J 2003;17:1541-1543.

16 Vogt CJ, Schmid-Schönbein GW: Microvascular endothelial cell death and rarefaction in the glucocorticoid-induced hypertensive rat. Microcirculation 2001;8:129-139.

17 Cipolla MJ, Bishop N, Vinke RS, Godfrey JA: PPAR \{gamma\} activation prevents hypertensive remodeling of cerebral arteries and improves vascular function in female rats. Stroke 2010;41:1266-1270.

18 Han B, Baliga R, Huang H, Giannone PJ, Bauer JA: Decreased cardiac expression of vascular endothelial growth factor and redox imbalance in murine diabetic cardiomyopathy. Am J Physiol Heart Circ Physiol 2009;297:H829-H835.

19 Emanueli C, Salis MB, Pinna A, Stacca T, Milia AF, Spano A, Chao J, Chao L, Sciola L, Madeddu P: Prevention of diabetes-induced microangiopathy by human tissue kallikrein gene transfer. Circulation 2002; 106:993999.

20 Kobayashi N, DeLano FA, Schmid-Schönbein GW: Oxidative stress promotes endothelial cell apoptosis and loss of microvessels in the spontaneously hypertensive rats. Arterioscler Thromb Vasc Biol 2005;25:21142121.

21 Romeo G, Liu WH, Asnaghi V, Kern TS, Lorenzi M: Activation of nuclear factor-kap$\mathrm{paB}$ induced by diabetes and high glucose regulates a proapoptotic program in retinal pericytes. Diabetes 2002;51:2241-2248.
22 Geraldes P, Hiraoka-Yamamoto J, Matsumoto M, Clermont A, Leitges M, Marette A, Aiello LP, Kern TS, King GL: Activation of PKC-delta and SHP-1 by hyperglycemia causes vascular cell apoptosis and diabetic retinopathy. Nat Med 2009;15:1298-1306.

23 Nishikawa T, Edelstein D, Du XL, Yamagishi S, Matsumura T, Kaneda Y, Yorek MA, Beebe D, Oates PJ, Hammes HP, Giardino I, Brownlee M: Normalizing mitochondrial superoxide production blocks three pathways of hyperglycaemic damage. Nature 2000;404: 787-790.

24 Biscetti F, Straface G, Arena V, Stigliano E, Pecorini G, Rizzo P, De Angelis G, Iuliano L, Ghirlanda G, Flex A: Pioglitazone enhances collateral blood flow in ischemic hindlimb of diabetic mice through an Akt-dependent VEGF-mediated mechanism, regardless of PPARgamma stimulation. Cardiovasc Diabetol 2009;8:49.

25 Gealekman O, Burkart A, Chouinard M, Nicoloro SM, Straubhaar J, Corvera S: Enhanced angiogenesis in obesity and in response to PPARgamma activators through adipocyte VEGF and ANGPTL4 production. Am J Physiol Endocrinol Metab 2008; 295:E1056-E1064.

26 Redondo S, Ruiz E, Santos-Gallego CG, Padilla E, Tejerina T: Pioglitazone induces vascular smooth muscle cell apoptosis through a peroxisome proliferator-activated receptor-gamma, transforming growth factor-beta1, and a Smad2-dependent mechanism. Diabetes 2005;54:811-817.

27 Billiet L, Furman C, Larigauderie G, Copin C, Page S, Fruchart JC, Brand K, Rouis M: Enhanced VDUP-1 gene expression by PPARgamma agonist induces apoptosis in human macrophage. J Cell Physiol 2008;214: 183-191.

28 Lindenmeyer MT, Kretzler M, Boucherot A, Berra S, Yasuda Y, Henger A, Eichinger F, Gaiser S, Schmid H, Rastaldi MP, Schrier RW, Schlöndorff D, Cohen CD: Interstitial vascular rarefaction and reduced VEGF-A expression in human diabetic nephropathy. J Am Soc Nephrol 2007; 18:1765-1776.

29 Thangarajah H, Yao D, Chang EI, Shi Y, Jazayeri L, Vial IN, Galiano RD, Du XL, Grogan R, Galvez MG, Januszyk M, Brownlee M, Gurtner GC: The molecular basis for impaired hypoxia-induced VEGF expression in diabetic tissues. Proc Natl Acad Sci USA 2009; 106:13505-13510.
30 Emoto M, Anno T, Sato Y, Tanabe K, Okuya S, Tanizawa Y, Matsutani A, Oka Y: Troglitazone treatment increases plasma vascular endothelial growth factor in diabetic patients and its mRNA in 3T3-L1 adipocytes. Diabetes 2001;50:1166-1170.

31 Chintalgattu V, Harris GS, Akula SM, Katwa LC: PPAR-gamma agonists induce the expression of VEGF and its receptors in cultured cardiac myofibroblasts. Cardiovasc Res 2007;74:140-150.

32 Arany Z, Foo SY, Ma Y, Ruas JL, BommiReddy A, Girnun G, Cooper M, Laznik D, Chinsomboon J, Rangwala SM, Baek KH, Rosenzweig A, Spiegelman BM: HIF-independent regulation of VEGF and angiogenesis by the transcriptional coactivator PGClalpha. Nature 2008;451:1008-1012.

33 Zolk O, Solbach TF, Eschenhagen T, Weidemann A, Fromm MF: Activation of negative regulators of the hypoxia-inducible factor (HIF) pathway in human end-stage heart failure. Biochem Biophys Res Commun 2008;376:315-320.

34 Blasi ER, Heyen J, Hemkens M, McHarg A, Ecelbarger CM, Tiwari S: Effects of chronic PPAR-agonist treatment on cardiac structure and function, blood pressure, and kidney in healthy Sprague-Dawley rats. PPAR Res 2009;2009:237865.

35 Yue Tl TL, Chen J, Bao W, Narayanan PK, Bril A, Jiang W, Lysko PG, Gu JL, Boyce R, Zimmerman DM, Hart TK, Buckingham $\mathrm{RE}$, Ohlstein EH: In vivo myocardial protection from ischemia/reperfusion injury by the peroxisome proliferator-activated receptorgamma agonist rosiglitazone. Circulation 2001;104:2588-2594.

36 Son NH, Park TS, Yamashita H, Yokoyama M, Huggins LA, Okajima K, Homma S, Szabolcs MJ, Huang LS, Goldberg IJ: Cardiomyocyte expression of PPARgamma leads to cardiac dysfunction in mice. J Clin Invest 2007;117:2791-2801.

37 Baraka A, AbdelGawad H: Targeting apoptosis in the heart of streptozotocin-induced diabetic rats. J Cardiovasc Pharmacol Ther 2010;15:175-181. 